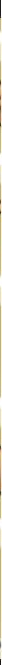

Editor:

Jaime Almansa Sánchez

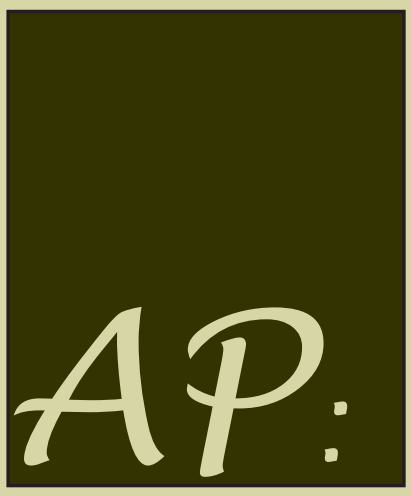

www.arqueologiapublica.es

Ontine Journat in Public Archaeology 


\title{
Public Archaeology via skyscraper: Outcome and Experience
}

\author{
Patrice L. JEPPSON \\ Philadelphia Archaeological Forum \\ Glen MUSCHIO \\ Drexel University. Digital Media Program, \\ College of Media Arts and Design \\ Hannah WINOGRAD
} Drexel University. STAR Fellowship Program, Pennoni Honors College Digital Media Program, College of Media Arts and Design

Matthew HAAS Drexel University. STAR Fellowship Program, Pennoni Honors College Digital Media Program, College of Media Arts and Design Geoffrey OXHOLM Drexel University. Computer Science Department Ko NISHINO Drexel University. Computer Science Department

The 3D Colonial Philadelphia Project - Digital Restoration of ThinShell Objects for Historical Archeological Research and Interpretation (National Science Foundation IIS Grant 0803670)

\section{Abstract}

A recent archaeology awareness campaign projected Public Service Announcements from the top of a city skyscraper. These 30-second videos featured animated $3 D$ artifact reconstructions alongside an archaeology-themed message. This was not just public archaeology done in an unusual way but public archaeology conducted toward an unusually broad end: the processes involved in creating the PSAs served many masters, not just archaeology's needs. This paper reports on this reflexive, dialogic, public archaeology case study where communities make use of the past for their own needs in the present.

\section{Key words}

New Media, Computational Archaeology, Convergence Theory, Dialogic Public Archaeology 


\section{Introduction}

What is that twirling around on top of that building? This was an anticipated response to an unusual archaeological awareness campaign launched in Philadelphia, Pennsylvania (U.S.A.) in the fall of 2011. The project involved the creation of public service announcements, or PSAs, that were projected on a 40 foot(10 meter)-tall LED light marquee encircling the 27th floor of a city skyscraper. (Figure 1). These PSAs featured 30-second long videos that drew upon local archaeological evidence and cutting edge computational archaeology research. The videos showcased animated 3D artifact reconstructions alongside archaeology-themed text rendered in eye-catching color. Lighting up the night sky akin to the media walls in New York City's "Times Square" or the Las Vegas (Nevada) "Strip", these electronic billboard messages aimed to stimulate public curiosity and thereby engender some awareness about local archaeology. The messages would be visible to an estimated 100,000 people each evening. To see a video of one of these PSAs in operation go to http://youtu.be/VFDcWm9INvs (Length: 0.33 seconds) *Need latest Acrobat to watch the videos 


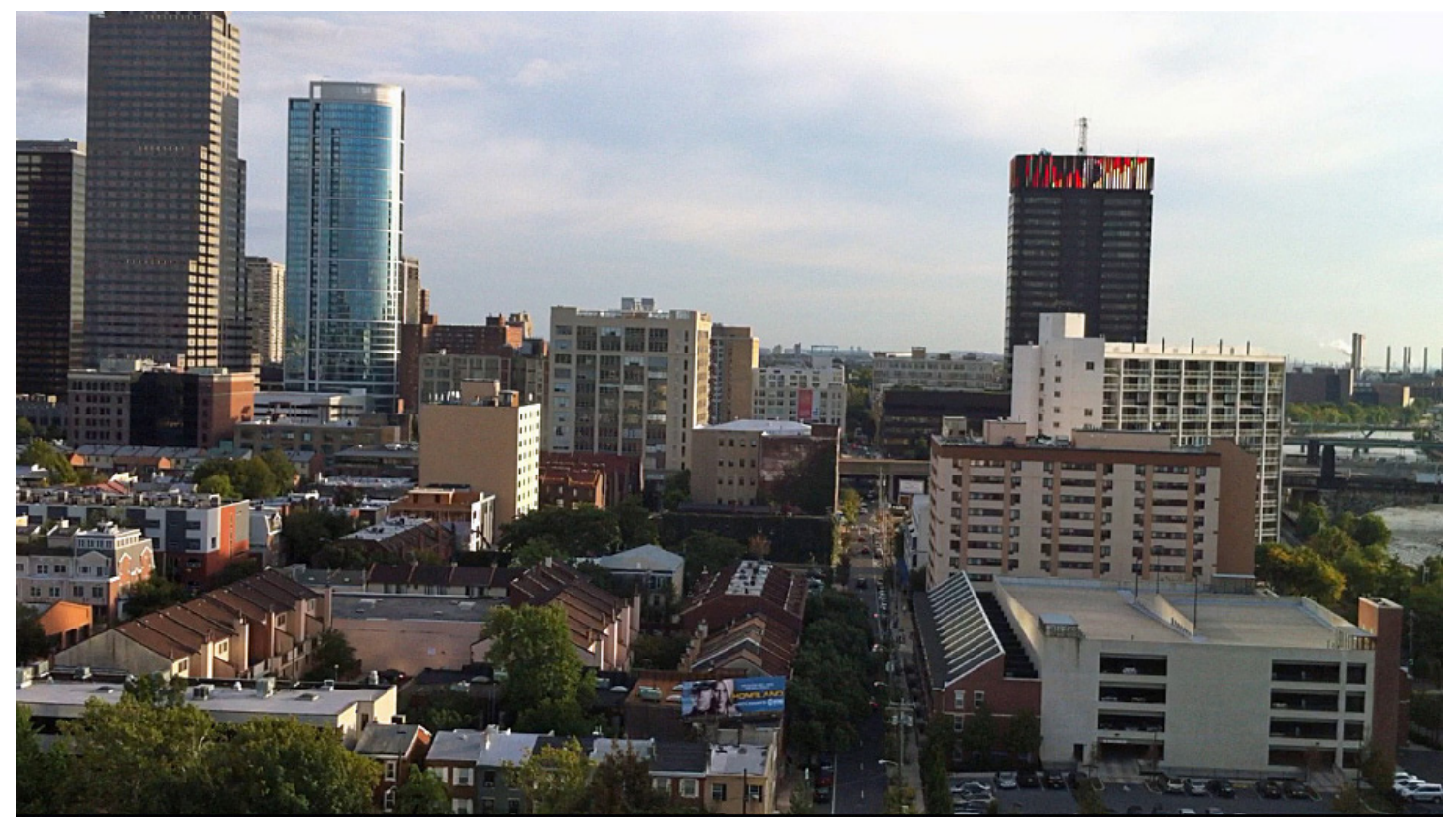

Figure 1. The skyscraper on the right shows one of the three 3D animated videos in operation just before sunset on September 28th, 2011. The local electric company broadcasts community service messages on this electronic billboard each evening from 5pm to 9am. (Photo by P. L. Jeppson, 2011).

However, from the first stages of planning it became clear that this public archaeology endeavor would be about much more than the finished and transmitted PSAs. It was evident that public archaeology infused the processes of creating the PSAs -if by public archaeology we mean the public's use of the past for its needs in the present. The 3D animated messages emerged through a convergence of computational archaeology research, new media education, as well as local archaeology needs, and as such they involved trans-disciplinary aims and goals. Added to this, the marquee hosting of the PSAs, courtesy of the local electric company, involved a corporation serving its own community relations' needs while serving ours. Thus, while the project would lead to a finished product that spread awareness about, and encouraged interest in, local archaeology, it also served many masters. It went beyond a public archaeology outreach aim of meeting archaeology's needs to serve the needs of various publics beyond archaeology's borders.

This paper looks behind the scenes of this particular project's collaborative form (production) and function (purpose). It explores the convergence of interests and expertise that procured, produced, and/ 
or facilitated the creation of the PSAs and their projection from the top of the building. Included is a contextual analysis of the various elements and constituencies involved -namely a treatment of the archaeological resources used in the project, a description and critique of the archaeology awareness campaign itself, a discussion and analysis of the collaborative partnerships that ensued, and a demonstration, via hyperlinked steaming YouTube videos, of the finished product.

The principles involved in this project, whose contributions are described below, are Glen Muschio, Matt Haas, Hannah Winograd, Geoffrey Oxholm, and myself, Patrice Jeppson - who serves as primary author of this paper. As the public archaeologist on this team, it is I who reports here on the project's public archaeology aspects. Toward this end, I anthropologically theorize this case study so as to explore the present of archaeology. I examine the relationship between archaeology and society as part of daily life through a systematic evaluation of the different social, economic, and/or political issues and interests surrounding the PSA endeavor. While data relevant for a quantitative assessment of the project's outcome is provided, this case study demonstrates the qualitative value of a reflexive, dialogic public archaeology (see Matthews et al., 2011).

\section{The Project as an Archaeology Month Contribution}

Most of the fifty states making up the United States of America celebrate an annual Archaeology Month or Week. These designations are created through proclamation by the Governors of the individual states and are designed to help generate understanding and interest in a state's archaeological heritage (for more see Archaeology for the public, State Archaeology Month Information 2011). In each locality, local professional archaeologists, avocational archaeologists and volunteers organize celebratory activities, often with local sponsorships. The Public Service Announcement project that I describe and analyze here is a local manifestation of one such statewide archaeological awareness campaign -in this case, involving archaeology month in the Commonwealth of Pennsylvania (as the state of Pennsylvania is known).

October is designated as Archaeology Month for Pennsylvania and celebrations take place annually throughout the Commonwealth including in the state's largest city of Philadelphia that, with 3.9 million 
persons in the broader metropolitan area, is also the nation's 5th largest urban concentration. For several years running, the major Philadelphia celebration has been a program of presentations, videos and occasional exhibits where local researchers come together to share the year's local discoveries with members of the general public (see, among others, Explore Philly's Hidden Past Program, 2011). This annual event is coorganized and co-sponsored by the Philadelphia Archaeological Forum (PAF) and the Archeology Lab at Independence National Historical Park (INHP). PAF is a non-profit organization dedicated to the protection and preservation of Philadelphia-area archaeological resources. INHP is a U.S. Department of the Interior National Park Service (NPS) unit located in the center of the city of Philadelphia. This annual event has involved as many as 21 archaeologists presenting prehistoric, historical, and industrial archaeology discoveries during a day-long conference created specifically with the general public in mind. As a local archaeologist who also has a research interest in public archaeology, I generally volunteer to undertake the publicity for this program. I do this as volunteered service to PAF, my local archaeological society. This year, my efforts involved the public service announcement project discussed here.

In the build up to the 2011 archaeology month celebration I decided to expand PAF's usual Archaeology Month publicity with a new undertaking that would help to showcase the area's rich archaeological resources while also highlighting both the annual event and the existence of PAF itself as an organization dedicated to local archaeological concerns. Toward this end, on behalf of PAF, I approached a new media researcher at Drexel University, Glen Muschio, about creating a digitally-rich public service announcement, or PSA, that could run on the local electric company's community service platform -an electronic billboard encircling the top of their corporate headquarters building used to promote local non-profit organizations and activities. Muschio has an on-going research interest in digital archaeology interpretation and preservation and is, as a result, also involved in the PAF. He suggested making two PSAs; one that would announce the specific details for the local annual event and another, more general in scope, to promote October as the state's Archaeology Month. This suggestion well suited PAF's needs. The event-specific PSA would supplement the already existing publicity campaign mounted for the annual event (purchased print ads, emailed announcements, and widely posted fliers) while the second PSA, promoting October as Pennsylvania Archaeology Month, would be a new Pennsylvania Archaeology Month contribution from PAF. 


\section{Archaeology Month as a Community Education Resource}

For his part, Muschio's involvement in the project had several direct and indirect benefits. Muschio's institution, Drexel University, is a top-ranked, comprehensive university that is recognized for its focus on experiential learning through co-operative education. Drexel is also known for its commitment to cutting-edge technology and its useinspired research. The PSA project could serve as course content for Muschio's instructional needs in the Program in Digital Media in Drexel's Antioinette Westphal College of Media Arts and Design. Founded and developed by Muschio, this program of study addresses the rapidly growing impact of new media on entertainment, education, and industry and the program's scholarship reflects the fast-paced, constantly evolving field in which art, technology and science intersect. The program offers college students Bachelor of Science degrees in Animation and Visual Effects, Game Art and Production, and Web Development. These major courses provide graduates with the technological, storytelling, and design skills to succeed in the highly competitive fields of entertainment, design, and new media. While creating the PSAs was not expected to require novel technological development, the project would serve as good practice for students needing practical experience with new media modeling or students learning animation. The PSA project would also comprise a class assignment with valuable real world application. Moreover, by partaking in the PSA project on behalf of the non-profit PAF, the Digital Media Program, Antoniette Westphal College, and Drexel University as a whole would be conducting campus outreach by assisting a local concern in the community.

With the PSA project in mind, Muschio selected two students from Drexel's Pennoni Honors College STAR Scholars Program for summer internships in the Digital Media Program. Inspired by Drexel's philosophy of learning by doing, the Students Tracking Advanced Research Fellowship Program (STAR) matches first-year students with facultymentored research or creative projects. This allows students to explore a major course of study and gain practical skills and valuable research experience for their future career. The students-Hannah Winograd and Matthew Haas - began development of the PSAs alongside another research project as part of their semester coursework. Muschio directed this student research and I, as archaeologist, served as a Mentor. 


\section{Designing the PSAs: The Archaeological, Political, and Technological Context}

The content comprising the PSAs was circumscribed by the electric utility's requirements that included, among other limitations, a message length of 72 characters translating into a 30-second long message. These requirements helped narrow the message to bare essentials. The first PSA would present the annual event's name and date and provide a URL leading to the scheduled program of talks (hosted at the PAF web pages). The second PSA would announce, "October is Pennsylvania Archaeology Month", followed by a URL leading to the PAF's main web page.

Given the options available through collaboration with the Drexel Digital Media Program, it was hoped that the PSAs could be more than the text-only messages routinely run on the electric company's marquee. PAF wanted images of local artifacts to illustrate the text. Muschio came up with an even better idea of using animated images -specifically short videos of artifacts that are first depicted in pieces that then merge together to form a whole artifact. He suggested using one artifact for the event-specific message and two artifacts for two different versions of the general Archaeology Month message.

There were no shortage of possible artifact candidates to use for these animations but PAF preferred objects representative of the cosponsoring Independence National Historical Park and, in particular, artifacts related to one particular Independence Park archaeological site -the site of the National Constitution Center (known as the NCC site). Excavated between 2000-2003, this archaeological site is now the location of the National Constitution Center museum and this institution (The NCC) had offered to host the annual archaeology month event that would be held in October. This hosting was offered by the NCC as a public service and as a gesture of good will as part of an archaeological compliance agreement (more on this below). [While the NCC is a government-sponsored, non-profit entity, and while it is located within Independence National Historical Park, it is not part of that National Park Service unit.]

Much more was going on in making this image request than meets the eye. The NCC museum rests upon what was arguably one of the largest and most artifact-rich deposits of material culture dating to the birth and early development of the United States. More than 1 million artifacts were recovered during the museum's construction that 
impacted a major swath of the colonial city of Philadelphia (most of a modern city block). The National Constitution Center is contractually obliged under federal legislation to complete the archaeological research on the material culture residues recovered from beneath their building. Independence National Historical Park, meanwhile, is the entity shepherding that legislated site compliance. However, promoting this extraordinary archaeological site is not something that INHP actively does. It is likewise not something that falls within The NCC museum's mission. Instead, the Philadelphia Archaeological Forum, an organization concerned with the archaeological resources of the city, serves as a major voice in getting word out about this site's existence and its extraordinary potential for new U.S. history insights. In making the PSA image request, PAF was promoting awareness about this important archaeological site and was also communicating to the power structures responsible for the research and stewardship of the collection excavated from the site.

PAF is formally registered as an Interested Party for the NCC site archaeology research that is being conducted as a joint project of INHP and The NCC. Interested Party status is part of the National Park Service's Management Policy for Consultation -dedicated to seeking, discussing, considering and learning from the views of others, and, where feasible, seeking agreement with them on how historic resources should be identified, evaluated, and managed (2006:13) - and also its Policy of Civic Engagement - concerned with building collaborative relationships between the service and American society (2006:14). PAF's desire to highlight NCC site artifacts in the PSAs was therefore not just an opportunity to showcase exceptional examples of material culture excavated from the city, from the NCC site, and from Independence Park. It was also an opportunity to remind the powers that be that an interested group remains vigilant in monitoring the government's and the NCC's cultural resource compliance responsibilities when it comes to the archaeology in the city of Philadelphia.

In short, this PSA project, and the decision to use NCC site artifacts as graphics for the PSAs, falls within PAF's mission which includes protecting and preserving archaeological resources in the City, furthering awareness of Philadelphia's rich archaeological heritage through educational programs and activities, and advising agencies and the general public on archaeological matters (Philadelphia Archaeological Forum Mission Statement 2010). PAF represents the city's broad constituents with members drawn from, among other groups, avocational archaeologists, architects, historians, journalists, 
schoolteachers, college students, community organizers, university researchers, private sector archaeologists, retired persons, preservation specialists, and museum professionals. As a dedicated consulting party on multiple city, state, and federal development projects taking place within the city limits, PAF serves as an archaeological resource "watchdog". It also regularly assists allied concerns, such as the Philadelphia Preservation Alliance, and local and special interest groups, such as the Philadelphia Neighborhood Alliance and the Delaware River Keeper. PAF actively promotes Philadelphia's archaeology as a community resource offering multiple benefits. This includes service opportunities to Philadelphians of all backgrounds and walks of life, not least of all school students, college interns, MA and PhD students, and retired citizen volunteers. PAF promotes local archaeology by cosponsoring publications and more recently a full-length, documentary film. Lastly, it operates a substantive informational web page about all things archaeological in the city of Philadelphia -an archive of original research/grey literature circa 1970-2010, lists of current archaeology events, online exhibits, featured articles, and local news coverage about the city's archaeology (www. phillyarchaeology.org).

In fulfilling its mission, PAF functions as a local concern with local Philadelphia citizens in mind. Much as in Rome, Italy, archaeology in Philadelphia is a mainstay of the city's main industry, which is heritage tourism. The archaeological residues in Independence National Historical Park, which commemorate the birthplace of American democracy, comprise a world Heritage site that is visited by millions of international visitors. These same ruins function as civil history and heritage touchstones for America's own citizens who visit during school trips and family vacations (see, among others, Jeppson 2007; 2006). African American historical archaeology sites in Independence Park serve as powerful rallying points for local and national African American social identity (Levin 2011; Jeppson et. al. 2009). But it is not uncommon for a local populace to remain indifferent to the "tourist sites" in their own backyard. Such is the case with the residents of the city of Philadelphia. As a result, PAF works to generate local awareness about, and interest in, local archaeology among the broader Philadelphia-area community -including awareness about PAF itself as an open-membership, local citizens group dedicated to preserving and educating about that archaeology. The PSA project would go a good way toward serving this end. 


\section{The Archaeology in the Public Service Announcements}

The archaeological evidence selected for use in the public service announcements is a miniscule representation of the vast assemblage recovered from the site of the National Constitution Center in Independence National Historical Park (Independence National Historical Park Archeology and National Constitution Center Web Page 2008). Between 1750 and 1850, this site was a densely populated and socially and economically diverse neighborhood. Nearly 1 million objects dating to the 18th and 19th centuries were excavated at this site from more than 200 artifact-bearing shaft features and 1100 square feet of original backyard ground surface. Among the vast range of evidence recovered were more than 300,000 ceramic fragments. To date, more than 1100 vessels have been reconstructed from this ceramic assemblage and three of these vessels were selected for use in the PSA animations. These include a small, hand-painted, pearlware saucer that accompanied the words, "Explore Philly's Hidden Past! 10/1 www. phillyarchaeology.org". A dipt' or annularware bowl, and a blue transfer-print-decorated plate, were featured, respectively, in the two general messages announcing, "October is Pennsylvania Archaeology Month www.phillyarchaeology.org" (Figures 2, 3, and 4). Both versions of the general message also featured a keystone (a wedge-shaped stone from the top of an arch) denoting the state of Pennsylvania's nickname, "The Keystone State".
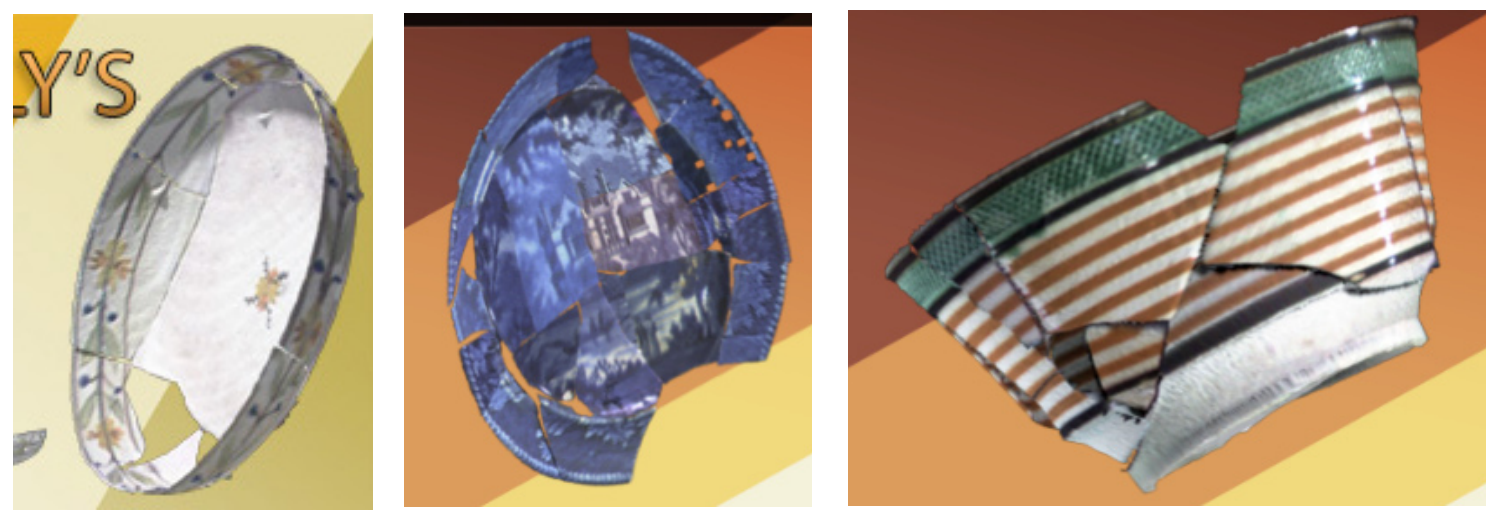

Figure 2, 3, and 4. Still photographs of the NCC/INHP ceramics used as images in the animated 3D PSAs. (Images based on research by G. Oxholm, animated by $\mathrm{H}$. Winograd and M. Haas, 2011.) 
Patrice L. JEPPSON et al. - Public Archaeology via skyscraper - 65

\section{The PSAs as Computational Archaeology Broader Impacts}

The ceramic images used to illustrate the PSAs came to the project courtesy of local computational archaeology research. For the past three and a half years, a subset of the NCC site ceramic remains have functioned as the research medium for Drexel University research, developing new 3D computer applications. That project, The 3D Colonial Philadelphia Project - Digital Restoration of Thin-Shell Objects for Historical Archeological Research and Interpretation is an experiment in the rapidly growing field of computational archaeology where conventional archaeological data is used for purposes of analysis, interpretations and exposition in specially designed software and applications. While typically involving geographical information systems, statistical or mathematical modeling, and simulations, in this project it is archaeological ceramic analysis that lends itself to the application of computational vision enabling technology (see The $3 D$ Colonial Philadelphia Project Web Page 2011). The objective of this research is to develop novel computer vision technology that will assist the ceramic artifact reconstruction process - if not fully automate it - thus enabling timely analysis, interpretation, and presentation of archaeological findings. This research is funded by the National Science Foundation Information and Intelligent Systems Division, specifically the Information Integration and Informatics Cluster III (grant award no. 0803670, 2008-2011, extended one year to 2012).

The 3D Philadelphia Project research involves researchers from five different fields working collectively to seek the 3D frontier; Computer scientist and electrical engineer Fernand Cohen (Grant PI) who researches virtual reconstructions using convex hulls of surface markings, computer scientist Ali Shokoufandeh (Co-PI) who is developing pattern classifications for reconstructions using texture and color descriptors, computer scientist Ko Nishino (Co-PI) who works in Image Registration and 3D recognition, new media specialist Glen Muschio (Co-PI) who is working on a long term virtual history interpretation and presentation project of the Philadelphia area, and myself, Patrice L. Jeppson (Co-PI), an historical archaeologist with a research interest in public archaeology, who facilitates the archaeological data set while also conducting ethnographic research (see, among others, Cohen 2010; Jeppson 2011, 2010; Jeppson et. al. 2011; Shokoufandeh et al. 2010, and The 3D Philadelphia Project project web page for Publications 2011). Research access to the NCC archaeological assemblage is provided courtesy of archaeologists Jed 
Levin, Deborah Miller and William Hoffman of the Archeology Lab at Independence National Historical Park.

The computational scientists, along with their students, are interested in the NCC ceramic remains because of their "thin" composition. Ceramic shapes are formed by a thin smooth surface rather than a solid volume and, in the vernacular of computational language, constitute "thin-shell" objects. The grant research employs the NCC ceramic remains toward the development of novel computer vision technologies that will reconstruct thin shell objects (aka ceramic vessels) in 3D (three dimension). Toward this end, the computational researchers appreciate the ceramic artifact shapes and designs that are useful for writing the mathematical algorithms that are central to the computer vision and pattern recognition development. It is these algorithms that will allow for 3D computer reconstructions. In this research the archaeology functions as a proxy medium. Once developed, such 3D computer vision applications will have real world implications for any and all convex shapes and their reconstructions, not just archaeology ceramics.

The PSAs drew upon this computational research, especially that being conducted in Drexel University's Department of Computer Science -home to research and education programs in software engineering, artificial intelligence, cognitive modeling and human computer interaction, computer vision and graphics, high performance computing, networks and security, symbolic computation, and computer science education. In particular, it involved the work of Computer Science PhD student, Geoffrey Oxholm. Oxholm, working with NSF grant Co-PI Nishino, has developed cutting edge software that virtually reassembles broken artifacts by using features found on the edges of ceramic fragments (Oxholm and Nishino 2011a, 2011c). This work utilized several of the cups, plates, and bowls recovered from the NCC site excavations. These vessels and their fragments were scanned with a 3D Minolta scanner and the resulting digital images were used for modeling the automated artifact reconstructions. In specific, Oxholm's application makes use of the color and shape features on the broken fragment edge (boundary contour) to create a colorful image that is then used to find and validate possible matching fragments. (Figure 5.) This process of identifying and validating candidate matching sherds is repeated until the object is reassembled. The application is demonstrated in the video presentation (2011b) Reassembling Thin Objects of Unknown Geometry, available for viewing on YouTube at http://youtu. be/HU7EumVM9Fc (Length: 2:15 minutes). 


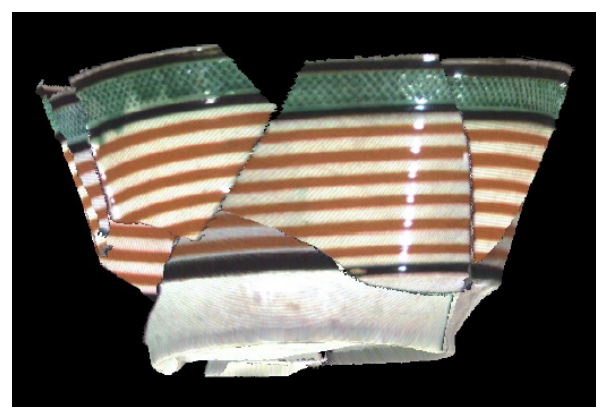

Figure 5. Vessel reconstructed using Oxholm's computer vision application. (Research image by Geoffrey Oxholm, 2011.)

Oxholm provided Muschio's digital media students, Winograd and Haas, with three research files he had compiled (on 3 different vessels) for use in the PSAs. With Oxholm's assistance, Winograd and Haas rendered this scientific data for use in media design software. They then used the rendered 3D images to create the animations using the computer program Autodesk Maya. The three animated artifacts were then inserted into movies that Winograd and Haas made using the program Adobe Premier. The first eight seconds of each movie features one of the 3D vessels first presented as several fragments that then come together to form a mended vessel. The reconstructed 3D vessel then rotates several times and then fades out. (Initially the object continued to rotate over the scrolling text message). The remaining twenty-two seconds of each PSA is a "running ribbon" of letter text set against a vibrant color pallet of oranges and yellows. The color choice was selected by Winograd and Haas to compliment the colors of the fall season. This text portion of the PSA was created using Adobe Photoshop.

The PSA creation process involved four iterations. Refinements were made to the color pallet and the degree of shadowing effect. The margin and the saturation level of the text letters were also adjusted to ensure better readability. Winograd and Haas' stated design goal was a visually striking but sophisticated presentation that was not too cluttered. The conceptual idea was that the PSAs animation sequence would first capture the viewer's attention, then the message would be read -with the viewer hopefully understanding the message's intent. 
Importantly, the translation of Oxholm's science files for media use revealed an unexpected complication relevant for computer science and new media researchers: Science rendered files are not easily made suitable for entertainment or education media uses, while the color spectrum typically found in computational science research is not the best choice for design needs. Winograd and Haas found that the tools commonly used in the media design environment to convert files wouldn't work with Oxholm's files. Indeed, they and Muschio discovered that the standard format computer science PLY file is not known to digital media students at all. This difference in format, revealed by the PSA project, possibly explained an early problem faced in the NSF grant research. Initially, digital media students were tasked with making the 3D scans of the NCC ceramic fragments and not all of the computer scientists and engineers involved in the NSF project were able to use the resulting images. As Muschio explained the problem, "the difference between computer science and media arts is like Mac versus PC, or like being a Chevy family or a Ford family" (referring to car company loyalty). This small matter, which has significant implications, was a valuable finding for the 3D Philadelphia Project's aim of turning computational science data into media assets viable for public history interpretation. Thanks to the PSA project, these first NSF grant research files are now in a format offering media versatility so the material can be used for multiple audience aims.

For Muschio, Winograd and Haas the PSA development process was a valuable academic learning experience. The project gave the students practice with teamwork and with meeting client demands. They learned new software programs (namely video editing) and new ways of doing things with programs they were already familiar with. They improved upon what they knew while also learning to work in the multi-disciplinary environment that is the 21st century culture of education. Winograd and Haas presented a professional research poster on the PSA project at the STAR Research Day, a practicum required by all STAR students at the end of the summer term. (Figure 6 and 7; Showcase Poster [pdf file 12120K].) There, upon seeing the research results (then approaching conclusion), the Dean of the College requested the PSAs for use on the school's webpage. 
Patrice L. JEPPSON et al. - Public Archaeology via skyscraper - 69

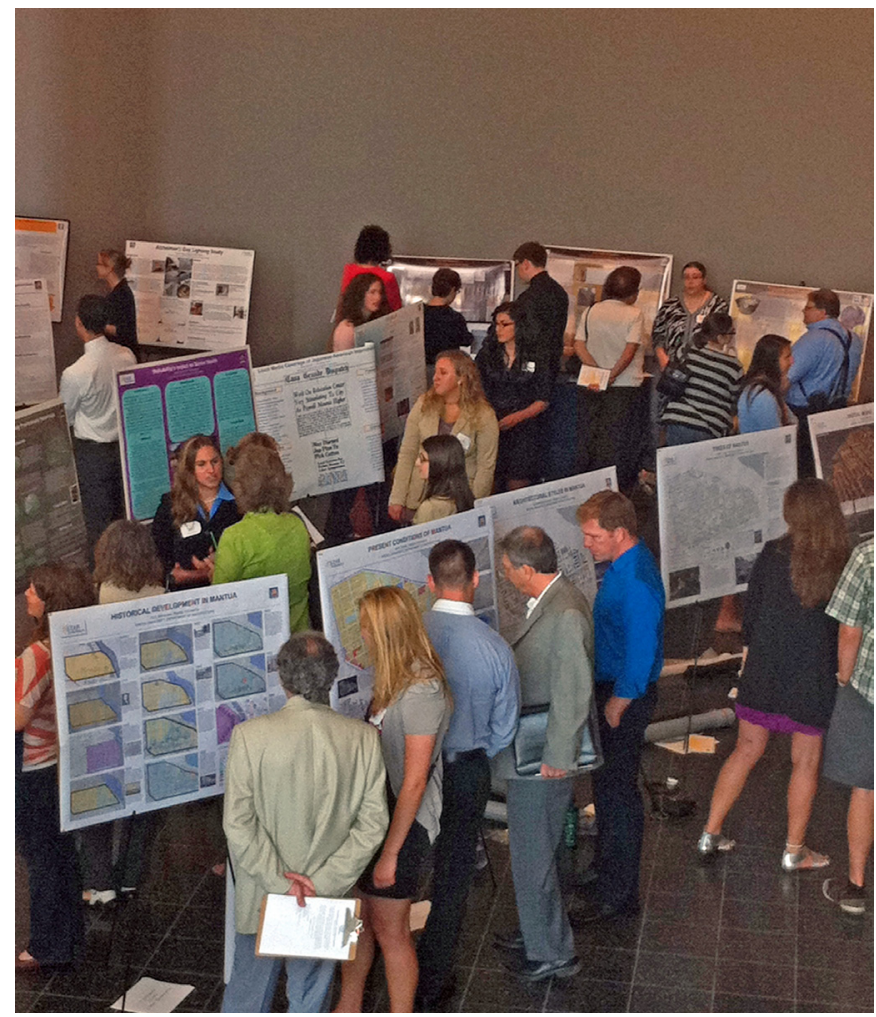

Figure 6. The PSA project was presented at Drexel University's Penoni Honors College, STAR Student Summer Showcase (Photo: P. Jeppson, 2011)

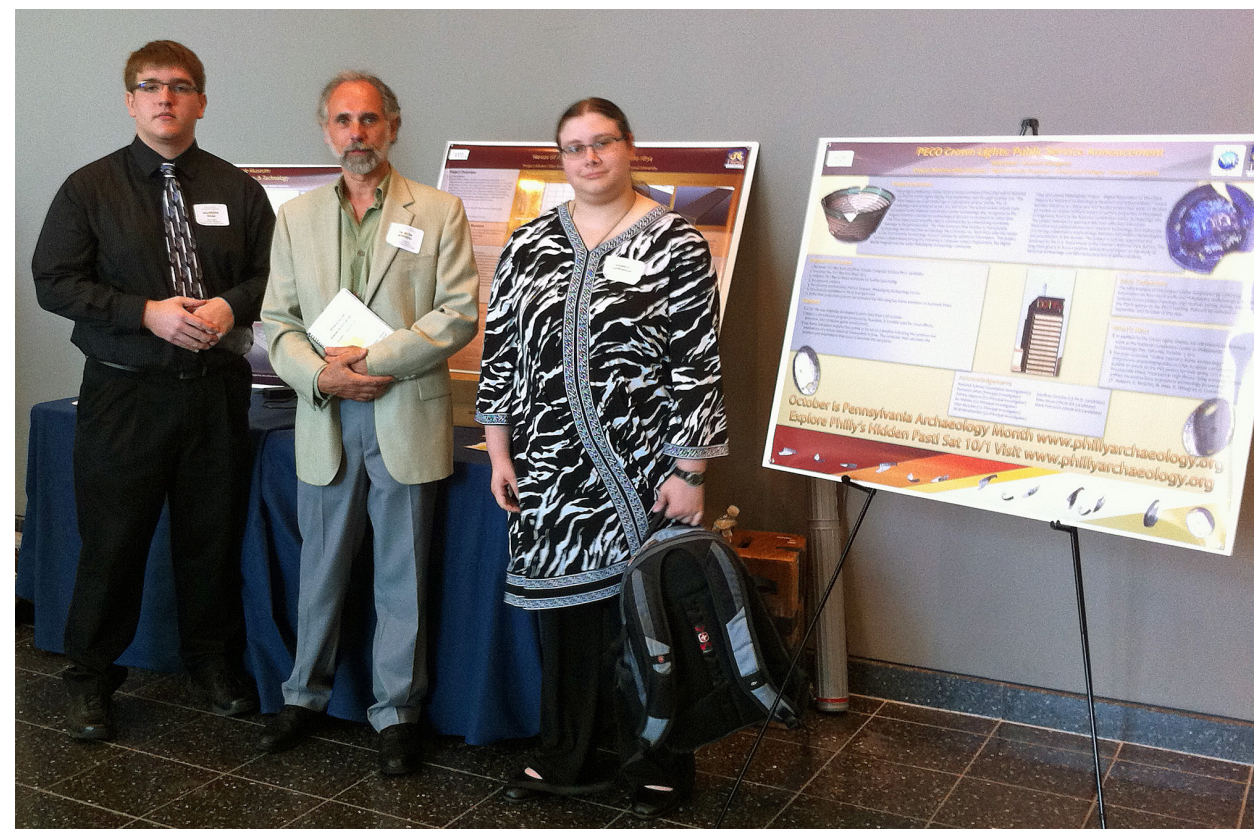

Figure 7. Matthew Haas, Glen Muschio, and Hannah Winograd with the poster presenting the PSA project (Photo: P. Jeppson, 2011) 
On a more pragmatic level, the project's development process constituted public outreach for both Oxholm and for the Drexel University Computer Science Department. It represented cross-department collaboration between the Computer Science and Media Arts schools, and it produced broader impacts relevant for the NSF grant research under the "public outreach" and "contributions to other disciplines" categories (see The 3D Philadelphia Project Broader Impacts 2011). Meanwhile, the Archeology Lab at Independence National Historical Park had made publicly available some of the park's cultural resources and did so for local educational concerns. This assisted the park in building bridges to local community institutions.

\section{Archaeology Awareness as a Community Service: the PSAs and the Crown Lights Marquee}

The PSAs were crafted to fit a unique electronic billboard configuration that has been part of the Philadelphia skyline since 1976. Known as the Crown Lights Marquee, this billboard encircles the top of the 27-story tall, downtown headquarters of the Philadelphia Electric Company known as PECO -the largest electricity and natural gas utility in Pennsylvania serving more than 1.5 million electric customers and a half million natural gas users. PECO is a hundred year old company that is widely recognized for its community service and economic development and, more recently, for its environmental efforts. For the past 35 years PECO has used its Crown Lights Marquee to salute local community and non-profit organizations. It has run 17,500 messages on behalf of these concerns as a community service. This is just one of several community ventures PECO has undertaken as a business leader trying to make a difference in the community (PECO Sponsorships and Programs Web Page 2002-2009).

The Crown Lights Marquee is formed by an electronic billboard made up of two exceptionally wide screens, each of which covers a long and a short side of the building (the east and south sides, and the north and west sides). These screens are themselves comprised of a long series of columns of lights with blank spaces in between. The rows upon rows of columns, in turn, hold two million LEDs, or lightemitting diodes. These columns of lights are 40 feet tall (approximately 10 meters high). The LED's are part of PECO's 15 million dollar Green Initiative whereby the utility aims to help preserve the environment 
and help customers become more environmentally responsible (PECO Environment Web Page 2002-2009).

With much fanfare, the billboard was recently renovated with the LED system replacing 2600 screw-in, incandescent light bulbs. The new system uses approximately 40 percent less energy while offering more options. The billboard is now capable of displaying full color text and graphics, including detailed animations, while the old system allowed only white letter text scrolling as a ribbon across the screen. However, except for in-house (PECO-created) messages, and one local business association's message, the PSAs projected using the LED screens are, to date, merely colored versions of the white letter messages projected since the marquee's debute in 1976 . This is likely because the unusual aspect ratio of the screens requires a specific image resolution $(2,224$ pixels wide and 360 pixels high) and the nonprofits requesting Crown Light messages have neither the technical expertise nor the time to devote to crafting a more technically rich message. Fortunately, the Philadelphia Archaeological Forum was able to do so through its collaboration with the Drexel Media Arts Program.

Early in the fall, Muschio presented Winograd and Haas' message designs in storyboard form to PAF and to Independence Park (archaeologist Jed Levin) for content and aesthetic design approval, and to PECO's Crown Lights coordinator for technical approval. The latter forwarded the storyboards to the Crown Lights installation firm (the YESCO company) to confirm the PSAs projection viability. All agreed with Winograd and Haas that the animated 3D object's rotation in the video needed to be slowed down and PECO requested that the object fade out rather than float in front of the text ribbon for the duration of the message. Winograd and Haas finalized the videos and Muschio provided them to PECO for projection. These were lower resolution videos of $72 \mathrm{dpi}$ (dots per square inch). The file size in toto was 100 Megabytes. The final PSA videos can be viewed on YouTube (Note: these are large file downloads). The "Explore Philly's Hidden Past! 10/1 www. phillyarchaeology.org" PSA is posted at http://youtu.be/CGfMGwsvvs (229MB). Version 1 of the "October is Pennsylvania Archaeology Month www.phillyarchaeology.org" PSA is posted at http://youtu.be/ xRJBG2E7WMM (363.9MB) and version 2 can be found at http://youtu. be/HejvRJv9eL4 (343.9MB). 
Patrice L. JEPPSON et al. - Public Archaeology via skyscraper - 72 
Patrice L. JEPPSON et al. - Public Archaeology via skyscraper - 73

\section{The Finished Product in Operation}

PECO operates their Crown Lights Marquee from $5 \mathrm{pm}$ to $9 \mathrm{am}$ each evening, projecting public service announcements requested by local community and non-profit groups. These are presented in rotation with the time and temperature. Approximately eight PSAs are run each quarter hour alongside rotating PECO-specific messages. The block of messages is repeated so that each PSA is projected approximately 4 times an hour for 16 hours, or 64 times each night.

The projected PSAs can be viewed from all directions and can be seen from as far away as 4 miles. The lighted messages even reflect on the adjacent Schuylkill River. PECO estimates that 100,000 persons a night can see the messages. While this is quite a number of viewers, it is a small portion of the city's population.

PECO agreed to run our event-specific PSA during the last week of September, just prior to the PAF/INHP Explore Philly's Hidden Past event that would be held on October 1st. This scheduling would help announce the event while also highlighting local archaeology. PECO would run one of the two general messages during the first week of October, the month designated as Archaeology Month in Pennsylvania. PECO would rotate the second general message into the PSA mix when there was space available elsewhere during the month.

Importantly, I considered the PSA project to be an act of public outreach in itself. I was happy to have these media art products as a new archaeology month offering, regardless of any responses that would or would not be garnered courtesy of the specific PSA message content. It was never assumed by me that archaeology month generally, nor the local archaeology month event specifically, would be of interest to all those who might see the PSAs. My hope was that the PSAs would target those who never thought about archaeology and who are not particularly interested in the subject. While the PSAs might play a role in getting word out about this year's local event, the main channels for announcing that were otherwise established -newspaper listings, print ads, listserv notices, mailings, and word of mouth. I would be satisfied if viewers of the PSAs merely read the word "archaeology" during the month of October when they otherwise might not have, and if some wondered why archaeology was being presented on the Crown Lights -even if they never acted upon their curiosity. Some of the viewers, but by no means all, would, I presumed, be motivated to look up the web page URL included in the PSAs. That development might or might 
not generate new attendance for the Explore Philly's Buried Past event. But that was almost beside the point. As far as I was concerned, the PSAs were an event of "public archaeology" all on their own.

This possibility of successfully targeting less interested publics is not something that can be evaluated by the web traffic statistics generated by the URLs in the PSAs. The web logs for those URLs do indicate a sharp increase in the number of original visitors during the periods when the PSAs were running on the marquee. (Figures 8 and 9). However, the statistics present a relative comparison against a nominal total number of visits. While the traffic statistics will appear interesting to some, others will find them inconsequential. Interestingly, not all the visits occurring during the PSA runs occur during the overnight hours -meaning that some visitors likely looked up the URLs during the daytime after seeing the PSA the evening before. This would suggest that the PSAs were successful in generating some curiosity or interest that was followed up on by members of the public engaging with the web page's archaeology information.

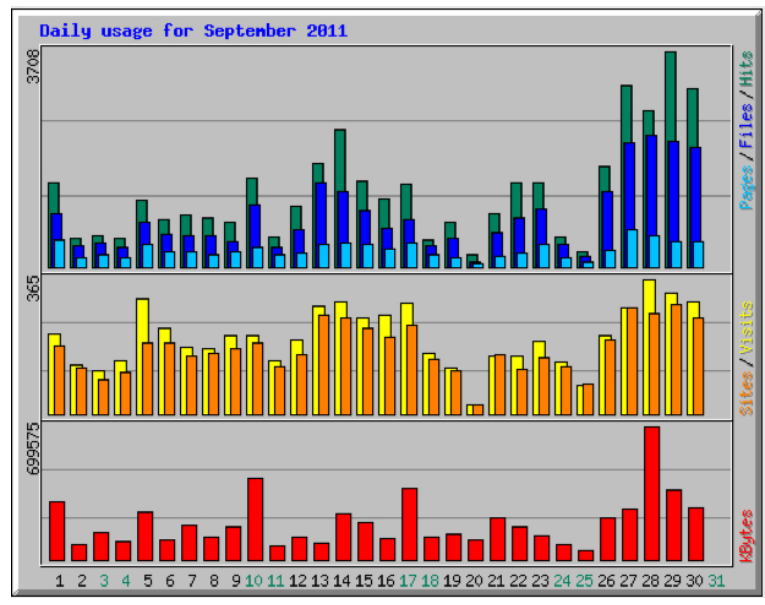

\begin{tabular}{|c|c|c|c|c|c|c|c|c|c|c|c|c|}
\hline \multicolumn{13}{|c|}{ Daily Statistics for September 2011} \\
\hline Day & \multicolumn{2}{|c|}{ Hits } & \multicolumn{2}{|c|}{ Files } & \multicolumn{2}{|c|}{ Pages } & \multicolumn{2}{|c|}{ Visits } & \multicolumn{2}{|c|}{ Sites } & \multicolumn{2}{|c|}{ KBytes } \\
\hline 1 & 1448 & $3.70 \%$ & 929 & $3.56 \%$ & 467 & $5.22 \%$ & 216 & $3.46 \%$ & 183 & $7.26 \%$ & 304278 & $5.15 \%$ \\
\hline 2 & 482 & $1.23 \%$ & 361 & $1.38 \%$ & 155 & $1.73 \%$ & 134 & $2.15 \%$ & 126 & $5.00 \%$ & 80375 & $1.36 \%$ \\
\hline 3 & 544 & $1.39 \%$ & 409 & $1.57 \%$ & 224 & $2.50 \%$ & 117 & $1.88 \%$ & 94 & $3.73 \%$ & 144184 & $2.44 \%$ \\
\hline 4 & 502 & $1.28 \%$ & 332 & $1.27 \%$ & 165 & $1.84 \%$ & 145 & $2.33 \%$ & 112 & $4.44 \%$ & 93029 & $1.57 \%$ \\
\hline 5 & 1154 & $2.95 \%$ & 770 & $2.95 \%$ & 387 & $4.32 \%$ & 311 & $4.99 \%$ & 192 & $7.62 \%$ & 248552 & $4.20 \%$ \\
\hline 6 & 815 & $2.08 \%$ & 578 & $2.22 \%$ & 262 & $2.93 \%$ & 231 & $3.71 \%$ & 194 & $7.70 \%$ & 106394 & $1.80 \%$ \\
\hline 7 & 902 & $2.30 \%$ & 540 & $2.07 \%$ & 275 & $3.07 \%$ & 181 & $2.90 \%$ & 157 & $6.23 \%$ & 178182 & $3.01 \%$ \\
\hline 8 & 850 & $2.17 \%$ & 553 & $2.12 \%$ & 218 & $2.43 \%$ & 177 & $2.84 \%$ & 165 & $6.55 \%$ & 122005 & $2.06 \%$ \\
\hline 9 & 765 & $1.95 \%$ & 445 & $1.71 \%$ & 254 & $2.84 \%$ & 214 & $3.43 \%$ & 177 & $7.02 \%$ & 172417 & $2.92 \%$ \\
\hline 10 & 1527 & $3.90 \%$ & 1061 & $4.07 \%$ & 341 & $3.81 \%$ & 213 & $3.42 \%$ & 192 & $7.62 \%$ & 430160 & $7.28 \%$ \\
\hline 11 & 506 & $1.29 \%$ & 353 & $1.35 \%$ & 204 & $2.28 \%$ & 143 & $2.29 \%$ & 127 & $5.04 \%$ & 75456 & $1.28 \%$ \\
\hline 12 & 1052 & $2.69 \%$ & 648 & $2.48 \%$ & 241 & $2.69 \%$ & 202 & $3.24 \%$ & 162 & $6.43 \%$ & 120039 & $2.03 \%$ \\
\hline 13 & 1774 & $4.53 \%$ & 1442 & $5.53 \%$ & 396 & $4.42 \%$ & 290 & $4.65 \%$ & 268 & $10.63 \%$ & 87874 & $1.49 \%$ \\
\hline 14 & 2349 & $6.00 \%$ & 1299 & $4.98 \%$ & 415 & $4.63 \%$ & 303 & $4.86 \%$ & 261 & $10.36 \%$ & 242998 & $4.11 \%$ \\
\hline 15 & 1485 & $3.79 \%$ & 966 & $3.70 \%$ & 380 & $4.24 \%$ & 260 & $4.17 \%$ & 234 & $9.29 \%$ & 194277 & $3.29 \%$ \\
\hline 16 & 1182 & $3.02 \%$ & 677 & $2.60 \%$ & 319 & $3.56 \%$ & 267 & $4.28 \%$ & 210 & $8.33 \%$ & 110041 & $1.86 \%$ \\
\hline 17 & 1418 & $3.62 \%$ & 830 & $3.18 \%$ & 423 & $4.72 \%$ & 299 & $4.80 \%$ & 240 & $9.52 \%$ & 373496 & $6.32 \%$ \\
\hline 18 & 477 & $1.22 \%$ & 375 & $1.44 \%$ & 204 & $2.28 \%$ & 163 & $2.61 \%$ & 148 & $5.87 \%$ & 120167 & $2.03 \%$ \\
\hline 19 & 772 & $1.97 \%$ & 503 & $1.93 \%$ & 155 & $1.73 \%$ & 126 & $2.02 \%$ & 116 & $4.60 \%$ & 134604 & $2.28 \%$ \\
\hline 20 & 219 & $0.56 \%$ & 85 & $0.33 \%$ & 54 & $0.60 \%$ & 24 & $0.38 \%$ & 25 & $0.99 \%$ & 101902 & $1.72 \%$ \\
\hline 21 & 917 & $2.34 \%$ & 603 & $2.31 \%$ & 186 & $2.08 \%$ & 156 & $2.50 \%$ & 160 & $6.35 \%$ & 222140 & $3.76 \%$ \\
\hline 22 & 1461 & $3.73 \%$ & 848 & $3.25 \%$ & 231 & $2.58 \%$ & 155 & $2.49 \%$ & 120 & $4.76 \%$ & 172923 & $2.92 \%$ \\
\hline 23 & 1450 & $3.70 \%$ & 1003 & $3.84 \%$ & 397 & $4.43 \%$ & 198 & $3.18 \%$ & 154 & $6.11 \%$ & 125718 & $2.13 \%$ \\
\hline 24 & 527 & $1.35 \%$ & 403 & $1.54 \%$ & 163 & $1.82 \%$ & 141 & $2.26 \%$ & 127 & $5.04 \%$ & 77824 & $1.32 \%$ \\
\hline 25 & 262 & $0.67 \%$ & 194 & $0.74 \%$ & 93 & $1.04 \%$ & 78 & $1.25 \%$ & 80 & $3.17 \%$ & 47525 & $0.80 \%$ \\
\hline 26 & 1728 & $4.41 \%$ & 1295 & $4.96 \%$ & 286 & $3.19 \%$ & 214 & $3.43 \%$ & 199 & $7.90 \%$ & 222658 & $3.77 \%$ \\
\hline 27 & 3119 & $7.97 \%$ & 2131 & $8.17 \%$ & 640 & $7.15 \%$ & 287 & $4.60 \%$ & 288 & $11.43 \%$ & 264394 & $4.47 \%$ \\
\hline 28 & 2694 & $6.88 \%$ & 2248 & $8.62 \%$ & 542 & $6.05 \%$ & 365 & $5.85 \%$ & 271 & $10.75 \%$ & 699575 & $11.83 \%$ \\
\hline 29 & 3708 & $9.47 \%$ & 2150 & $8.24 \%$ & 434 & $4.85 \%$ & 329 & $5.28 \%$ & 294 & $11.67 \%$ & 365261 & $6.18 \%$ \\
\hline 30 & 3054 & $7.80 \%$ & 2057 & $7.88 \%$ & 443 & $4.95 \%$ & 304 & $4.88 \%$ & 260 & $10.32 \%$ & 274282 & $4.64 \%$ \\
\hline
\end{tabular}

Figure 8. Web Page logs for September 2011 indicate a sharp rise for period September 26th-30th when the event-specific PSA was in operation. 


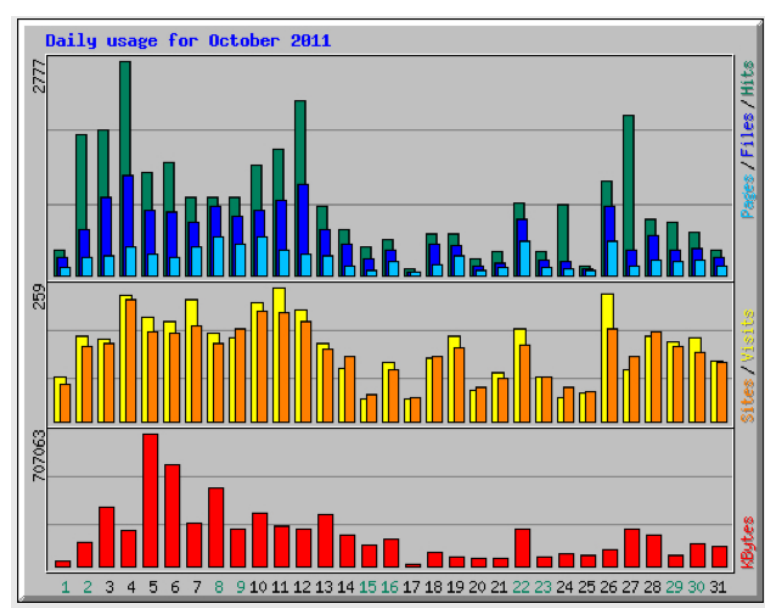

\begin{tabular}{|c|c|c|c|c|c|c|c|c|c|c|c|c|}
\hline \multicolumn{13}{|c|}{ Daily Statistics for October 2011} \\
\hline \multirow{2}{*}{$\begin{array}{c}\text { Day } \\
1\end{array}$} & \multicolumn{2}{|c|}{ Hits } & \multicolumn{2}{|c|}{ Files } & \multicolumn{2}{|c|}{ Pages } & \multicolumn{2}{|c|}{ Visits } & \multicolumn{2}{|c|}{ Sites } & \multicolumn{2}{|c|}{ KBytes } \\
\hline & 329 & $1.10 \%$ & 240 & $1.44 \%$ & 103 & $1.46 \%$ & 86 & $1.90 \%$ & 72 & $3.45 \%$ & 27931 & $0.51 \%$ \\
\hline 2 & 1822 & $6.10 \%$ & 595 & $3.57 \%$ & 236 & $3.35 \%$ & 166 & $3.67 \%$ & 146 & $7.00 \%$ & 124862 & $2.28 \%$ \\
\hline 3 & 876 & $6.29 \%$ & 1013 & $6.08 \%$ & 251 & $3.56 \%$ & 159 & $3.52 \%$ & 152 & $7.29 \%$ & 314993 & $5.75 \%$ \\
\hline 4 & 2777 & $9.30 \%$ & 1292 & $7.75 \%$ & 370 & $5.25 \%$ & 243 & $5.38 \%$ & 234 & $11.22 \%$ & 188068 & $3.43 \%$ \\
\hline 5 & 1328 & $4.45 \%$ & 837 & $5.02 \%$ & 270 & $3.83 \%$ & 201 & $4.45 \%$ & $\overline{172}$ & $8.25 \%$ & 707063 & $12.90 \%$ \\
\hline 6 & 1457 & $4.88 \%$ & 829 & $4.97 \%$ & 234 & $3.32 \%$ & 192 & $4.25 \%$ & 169 & $8.10 \%$ & 538092 & $9.81 \%$ \\
\hline 7 & 1005 & $3.37 \%$ & 693 & $4.16 \%$ & 365 & $5.18 \%$ & 235 & $5.20 \%$ & 185 & $8.87 \%$ & 226199 & $4.13 \%$ \\
\hline 8 & 1013 & $3.39 \%$ & 899 & $5.39 \%$ & 504 & & 169 & $3.74 \%$ & 150 & $9 \%$ & & $7.54 \%$ \\
\hline 9 & 1003 & $3.36 \%$ & 770 & $4.62 \%$ & 413 & $5.86 \%$ & 163 & $3.61 \%$ & 178 & $8.53 \%$ & 200268 & $3.65 \%$ \\
\hline 10 & 1432 & $4.80 \%$ & 838 & $5.03 \%$ & 507 & $7.19 \%$ & 229 & $5.07 \%$ & 212 & $10.16 \%$ & 283372 & $5.17 \%$ \\
\hline 11 & 1642 & $5.50 \%$ & 971 & $5.83 \%$ & 332 & $4.71 \%$ & 259 & $5.73 \%$ & 210 & $10.07 \%$ & 213960 & $3.90 \%$ \\
\hline 12 & 2257 & $7.56 \%$ & 1175 & $7.05 \%$ & 278 & $3.94 \%$ & 216 & $4.78 \%$ & 193 & $9.25 \%$ & 199912 & $3.65 \%$ \\
\hline 13 & 895 & $3.00 \%$ & 587 & $3.52 \%$ & 247 & $350 \%$ & 152 & $3.36 \%$ & 140 & $6.71 \%$ & 279258 & $5.09 \%$ \\
\hline 14 & 599 & $2.01 \%$ & 404 & $2.42 \%$ & 128 & $1.82 \%$ & 102 & $2.26 \%$ & 125 & $5.99 \%$ & 169731 & $3.10 \%$ \\
\hline 15 & 375 & $1.26 \%$ & 215 & $1.29 \%$ & 57 & $0.81 \%$ & 45 & $1.00 \%$ & 52 & $2.49 \%$ & 116366 & $2.12 \%$ \\
\hline 16 & 467 & $1.56 \%$ & 328 & $197 \%$ & 179 & $2.54 \%$ & 114 & $2.52 \%$ & 99 & $4.75 \%$ & 140631 & $2.57 \%$ \\
\hline 17 & 87 & $0.29 \%$ & 54 & $0.32 \%$ & 48 & $0.68 \%$ & 45 & $1.00 \%$ & 46 & $2.21 \%$ & 15107 & $0.28 \%$ \\
\hline 18 & 535 & $1.79 \%$ & 406 & $2.44 \%$ & 143 & $2.03 \%$ & 122 & $2.70 \%$ & 125 & $5.99 \%$ & 74369 & $1.36 \%$ \\
\hline 19 & 538 & $1.80 \%$ & 390 & $2.34 \%$ & 248 & $3.52 \%$ & 164 & $3.63 \%$ & 142 & $6.81 \%$ & 46673 & $0.85 \%$ \\
\hline 20 & 208 & $0.70 \%$ & 131 & $0.79 \%$ & 68 & $0.96 \%$ & 61 & $1.35 \%$ & 67 & $3.21 \%$ & 38922 & $0.71 \%$ \\
\hline 21 & 313 & $1.05 \%$ & 166 & $1.00 \%$ & 108 & $1.53 \%$ & 93 & $2.06 \%$ & 82 & $3.93 \%$ & 44947 & $0.82 \%$ \\
\hline 22 & 932 & $3.12 \%$ & 719 & $4.31 \%$ & 447 & $6.34 \%$ & 178 & $3.94 \%$ & 149 & $7.14 \%$ & 198521 & $3.62 \%$ \\
\hline 23 & 308 & $1.03 \%$ & 189 & $1.13 \%$ & 106 & $150 \%$ & 85 & $1.88 \%$ & 85 & $4.07 \%$ & 52819 & $0.96 \%$ \\
\hline 24 & 920 & $3.08 \%$ & 173 & $1.04 \%$ & 80 & $1.13 \%$ & 47 & $1.04 \%$ & 67 & $3.21 \%$ & 66719 & $1.22 \%$ \\
\hline 25 & 122 & $0.41 \%$ & 82 & $0.49 \%$ & 65 & $0.92 \%$ & 55 & $1.22 \%$ & 59 & $2.83 \%$ & 62048 & $1.13 \%$ \\
\hline 26 & 1217 & $4.08 \%$ & 905 & $5.43 \%$ & 437 & $6.20 \%$ & 247 & $5.46 \%$ & 180 & $8.63 \%$ & 88170 & $1.61 \%$ \\
\hline 27 & 2074 & $6.95 \%$ & 335 & $2.01 \%$ & 128 & $1.82 \%$ & $\overline{100}$ & $2.21 \%$ & 124 & $5.94 \%$ & 194930 & $3.56 \%$ \\
\hline 28 & 729 & $2.44 \%$ & 512 & $3.07 \%$ & 203 & $2.88 \%$ & 164 & $3.63 \%$ & 173 & $8.29 \%$ & 170670 & $3.11 \%$ \\
\hline 29 & 690 & $2.31 \%$ & 323 & $1.94 \%$ & 172 & $2.44 \%$ & 153 & $3.38 \%$ & 145 & $6.95 \%$ & 59240 & $1.08 \%$ \\
\hline 30 & 558 & $1.87 \%$ & 353 & $2.12 \%$ & 198 & $2.81 \%$ & 163 & $3.61 \%$ & 133 & $6.38 \%$ & 118412 & $2.16 \%$ \\
\hline 31 & 340 & $1.14 \%$ & 243 & $1.46 \%$ & 127 & $1.80 \%$ & 117 & $2.59 \%$ & 114 & $5.47 \%$ & 107079 & $1.95 \%$ \\
\hline
\end{tabular}

Figure 9. Web Page logs for October 2011 indicate a sharp rise during the first week of the month when the general PSA was in operation on the marquee. The second general PSA was used in the PECO Crown Lights rotation when there was space during the remainder of the month.

In any case, the web logs do not reflect in any way the number of people who presumably saw the PSAs and therefore experienced what can be considered a new episode of public archaeology. The web logs also do not reflect the audience members at the Explore Philly's Hidden Past event -approximately 200 people- who saw a talk that presented the PSA videos (Jeppson et al., 2011). Of the 105 attendees who signed in to that event, only one mentioned learning about the event from the message on the Crown Lights Marquee.

Beyond this, it is known that a write up of the project was done for the Drexel University Computer Science Department web page and that Drexel University and the Philadelphia Archaeological Forum both sent Press Releases about the project. These comprise ancillary "public archaeology" related to this project. The PSA project was likewise adapted as content for the PAF web pages. It produced postings for the PAF Facebook page and for the Facebook page associated with this journal. Indeed, one might go so far as to state that this formal reporting is, to an extent, also part of this project's "Public Archaeology". I have deliberately selected AP: Online Journal in Public Archaeology as the publication venue for this case study because this is an electronic- 
based, cyber publication. This means that this project's data -the animated 3D public service announcements- can be streamed as part of the publication. More importantly, in aiming to expand and improve access to public archaeology and public archaeology research, this journal is also published as "open-access". Reporting on the case study here offers another opportunity for our public service announcements to continue to be publicly available as a public service.

\section{Outcome Verses Experience in Public Archaeology}

This public archaeology project leveraged local archaeological resources, computer science research, and media arts expertise to promote archaeology awareness. It produced colorful, 3D, animated public service announcements, forming a unique and special Philadelphia contribution to Pennsylvania Archaeology Month. But as an example of public archaeology, this PSA project met much more than archaeology's needs. In bringing together science, art and technology, the project constructed a community of collaboration and participation where outside concerns used archaeology for their own needs. Toward this end, the archaeology functioned as material culture of the present. The archaeological data transformed and constructed everyday life in the here and now. It moved through different hands into different uses beyond the discipline's borders.

In demonstrating this dialogic process, this case study offers a cautionary lesson about evaluating public archaeology efforts. This reporting focuses on the processes of collaboration that produce the archaeology-themed public service announcements. The public's engagement with this archaeology registers as advocacy, academic learning, and as community involvement. These qualitative measures deserve to be as recognized, respected, and celebrated, as much as, if not more than, the traditional quantitative outcomes usually used to validate and evaluate public archaeology. As demonstrated here, public archaeology practiced with a dialectical methodology has tangible but less calculable results. It can elicit how communities use archaeology to better understand and reflect themselves. It can help archaeology to better ground its research in community-based needs. It can also help make transparent the facilitating role that archaeology and archaeologists play when a community uses the past for their needs in the present. 
In short, this PSA case study reveals the dichotomy that exists between outcome and experience in public archaeology - between quantitative and qualitative assessment, between discipline-based outcomes and dialogic-driven collaboration. It comes down to a distinction between a public archaeology that is the destination and a public archaeology that is the journey. It behooves us not to sacrifice our experience to outcome.

\section{Bibliography}

Archaeology for the public 2011. State Archaeology Month Information web page, hosted by the Society for American Archaeology at SAAWeb. http://www.saa.org/publicftp/ PUBLIC/resources/ArchMonth_2005.html

Cohen, F., Zhongchuan Zhang, Z. and Jeppson P. 2010. Virtual Reconstruction of Archaeological Vessels using Convex Hulls of Surface Markings. CVPR 2010 Conference Workshop Proceedings. IEEE Conference on Computer Vision and Pattern Recognition.

Explore Philly's Hidden Past 2006-2011. A Pennsylvania Archaeology Month celebration sponsored by the Philadelphia Archaeological Forum and the Archeology Lab at Independence National Historical Park. Philadelphia, Pennsylvania. http://phillyarchaeology.org/events/archmonth11.htm

Independence National Historical Park (INHP) 2008. Archeology and National Constitution Center, Web Page http://www.nps. gov/inde/archeology-and-national-constitution-center.htm

Jeppson, P.L. 2006. Which Benjamin Franklin - Yours or Mine?: Examining the responses to a new story from Franklin Court. In Ran Boytner, Lynn Swartz-Dodd and Ann E. Killebrew edited issue 'Archaeologically-Based Heritage Formulation in Overtly Politicized Environments'. Archaeologies, Journal of the World Archaeological Congress, 2(2): 24-51.

Jeppson, P.L. 2007. Civil Religion and Civically Engaged Archaeology: Researching Benjamin Franklin and the Pragmatic Spirit. In Barbara Little and Paul Shackel edited Archaeology as a Tool 
of Civic Engagement. Lanham Maryland: Alta Mira Press, 173202.

Jeppson, P.L. 2010. Archaeological Heritage of "We the People": Public Archaeology at Independence National Historical Park. AnthropologyNews, Theme Issue on Tourism. Newsletter of the American Anthropological Association. November, 2010, 5-6.

http://onlinelibrary.wiley.com/doi/10.1111/j.15563502.2010.51805.x/pdf

Jeppson, P.L. 2011a. Computational Archaeology: A New Way of Looking at Independence Park Ceramic Remains. Society for Pennsylvania Archaeology annual conference, April 2011.

Jeppson, P.L. 2011b. The Dynamics of Inclusion at the Dynamics of Inclusion in Public Archaeology Workshop Public Event. Archaeologies. Journal of the World Archaeological Congress 7(3) December.

Jeppson, P.L., Muschio, G. and Levin, J. 2011. Computational Mathematics, Convergence Culture, and the Creation of Archaeological Knowledge and Understanding. Invited Paper presented at the Society for Historical and Underwater Archaeology Annual Conference. Austin, TX. January.

Jeppson, P.L., Roberts, J. Lind K. and Levin, J. 2009. Public Archaeology at the President's House Site, in The Archeology of Freedom and Slavery, Excavations at the President's House Site in Philadelphia by D. Mooney, I. Wuebber, C. LaRoche, J. Levin, P. L. Jeppson, J. Roberts, and K. Lind Brauer. Prepared for the National Park Service and City of Philadelphia.

Levin, J. 2011. Activism Leads to Excavation: The Power of Place and the Power of the People at the President's House in Philadelphia. Archaeologies. Journal of the World Archaeological Congress. 7(3) December.

Christopher, M. McDavid, C. and Jeppson, P.L. (Eds). 2011. The Dynamics of Inclusion in Public Archaeology. Archaeologies. Journal of the World Archaeological Congress 7(3) December. 
National Park Service 2006. Management Policies: The Guide to Managing the National Park System. U.S. Department of the Interior, National Park Service. Washington D.C.

Geoffrey, O. and Nishino, K. 2011a Reassembling Thin Objects of Unknown Geometry. 12th International Symposium on Virtual Reality, Archaeology and Cultural Heritage VAST. Tuscany, Italy.

http://webcache.googleusercontent.com/search?q=cache:3 5yK9U1vnwUJ:https://www.cs.drexel.edu/ kon/publication/ GOxholm_VAST11.pdf $+\& c d=1 \& \mathrm{hl}=\mathrm{en} \& \mathrm{ct}=\mathrm{clnk} \& \mathrm{gl}=\mathrm{us}$

Geoffrey, O. and Nishino, K. 2011b. Reassembling Thin Objects of Unknown Geometry.

http://www.youtube.com/watch?v=HU7EumVM9Fc (Length: 2:15 minutes.)

Geoffrey, O. and Nishino, K. 2011c. Aligning surfaces without aligning surfaces. Applications of Computer Vision, IEEE Workshop 2011, Abstract, pages 174 - 181

PECO 2009. Environment Web Page, 2002-2009. http://uat. staging.peco.com/pecores/environment_and_community/ environment/

PECO 2009. Sponsorships and Programs Web Page, 2002-2009. http://uat.staging.peco.com/pecores/environment_and_ community/community/Sponsorships+and+Programs.htm

Philadelphia Archaeological Forum 2010. Mission Statement. http://phillyarchaeology.org/about.htm

Shokoufandeh, A., Smith, P. and Jeppson P.L. 2010. Classification of Archaeological Fragments Using Texture and Color Descriptors. CVPR 2010 Conference Workshop Proceedings. IEEE Conference on Computer Vision and Pattern Recognition.

The 3D Colonial Philadelphia Project - Digital Restoration of Thin-Shell Objects for Historical Archeological Research and Interpretation 2011. Project Web Page. National Science Foundation Grant Award No. 0803670m 2008-2011 (1 year 
extension 2012), NSF Information and Intelligent Systems Division, Information Integration and Informatics Cluster (III). Drexel University: Fernand Cohen, Principle Investigator, Ali Shokafunde, Ko Nishino, Glen Muschio and Patrice L. Jeppson Co-Principle investigators.

http://tsp.cs.drexel.edu/pmwiki/pmwiki.php

2011 The 3D Colonial Philadelphia Project Project web page, Broader Impacts Page. http://tsp.cs.drexel.edu/ pmwiki/pmwiki.php?n=INHPProject2. BroaderImpacts

2011 The 3D Colonial Philadelphia Project Project web page, Publications Page. http://tsp.cs.drexel.edu/pmwiki/ pmwiki.php?n=INHPProject. Publications 


\section{AP: Ontine Journat in Public Archaeology}

\section{Editor:}

Jaime Almansa Sánchez

Email: almansasanchez@gmail.com

Assistant editor:

Elena Papagiannopoulou

Edited by:

JAS Arqueología S.L.U.

Website: www.jasarqueologia.es

Email: jasarqueologia@gmail.com

Address: Plaza de Arteijo 8, T-2, 28029 - Madrid (Spain)

--

Cover Image: Storyboard for a PSA in Philly (H. Winograd and M. Haas)

Copyright (C) 2012 JAS Arqueología S.L.U. (edition) \& Authors (content)

ISSN: $2171-6315$

Quotation:

Jeppson, P. et al. 2012. Public Archaeology via Skyscraper: Outcome and experience. AP Journal Vol. 2, 55-80.

AP Journal is a peer-reviewed journal devoted exclusively to Public Archaeology. It is freely distributed online on the Website:

$$
\text { www.arqueologiapublica.es }
$$

You can also follow us on:

Blogger:

=- http://arqueologiapublica.blogspot.com/

Twitter:

http://twitter.com/APjournal

Facebook:

http://www.facebook.com/APJournal 